\title{
Aphasia in Taishan Culture Worldwide Communication*
}

\author{
Fen Tian \\ School of Foreign Languages and Literature, Taishan University, Tai'an, China \\ Email: susanhai227@163.com
}

Received 4 September 2015; accepted 25 September 2015; published 28 September 2015

Copyright (C) 2015 by author and Scientific Research Publishing Inc.

This work is licensed under the Creative Commons Attribution International License (CC BY). http://creativecommons.org/licenses/by/4.0/

c) (†) Open Access

\section{Abstract}

Aphasia will occur in cultural communication with no exception of Taishan culture to the world. This article analyses the cultural aphasia from aspects of communication, discusses the reasons and proposes the solutions which is a tentative study to Chinese traditional culture communication.

\section{Keywords}

Taishan Culture, Communication, Aphasia

\section{Introduction}

In the process of teaching Chinese Culture (English Version) to the English major students, I am confronting a problem: students are skilled in speaking English; however they will be speechless, blank minded, and exhausted in speaking when they are to express and explain Chinese cultures. And this problem is also very popular among teachers in describing some typical Chinese cultural phenomena. As in the academic field, these phenomena of wordlessness, short circuit and fracture in language and culture expressions are regarded as aphasia.

\section{Research Background}

\subsection{The Application of Medical Term Aphasia into Literature Review}

Aphasia, originally, is a medical term which refers to "a collection of language disorders caused by damage to the brain" ${ }^{1}$. Later, Chinese scholar Cao Shunqing quoted this term and applied it into the description of criticiz-

\footnotetext{
"This paper is one of the results of Shandong Provincial Department of Culture project "Aphasia in Tiashan Culture Communication and the Corresponding Proposals” (No. Z2014056).

${ }^{1}$ Aphasia: http://en.wikipedia.org/wiki/Aphasia.
} 
ing the intrusion of western literature review to Chinese literature review in 1995 (Cao, 1995). Then in 1996a, 1996b, 1997, 2006, etc., he restated the problem of aphasia in Chinese literature review and its corresponding solutions. In 2000, in Guangming Daily, Professor Cong Cong published the article The Defect of Our English Teaching, mentioning that many high-level English major students had proficiency in speaking English, whereas, they would be speechless when communicating with foreigners in explaining Chinese cultures, especially those with particularly profound Chinese knowledge and thoughts such as Confucianism/Taoism. This article aroused scholars' interests to discuss aphasia from the point of view of foreign language teaching (Zhang, 2002; Ma, 2007; Zhang, 2009), cross-cultural communication (Chen, 2010), so on and so forth. These studies concerning aphasia focus on teaching, learning and the ways of avoiding aphasia from the aspect of domestic English teaching, but not from the aspect of Chinese culture propagation to the world, not to mention the inconsistencies or misunderstandings in the procedure of communication, and still less mentioning of the reasons of how the corresponding aphasia occurs. Therefore this paper is an elementary study of how the aphasia appears from the theoretical background of Cultural Communication to explore in what aspects the aphasia occurs, the reasons and proposals of dealing with the problems, by taking the external communication of Taishan Culture as an instance.

\subsection{Background of Taishan Culture Worldwide Communication}

Taishan culture gains its popular dissemination to the world under the help of foreign Missionaries, travelers and sinologists. According to the research of Zhou Ying (Cultural Exchange between China and Foreign Countries, 2009), Taishan Culture spread to the world from a very ancient time. In the Western Han Dynasty, envoys from Anxi (Iran) and Suxie (Countries in the West) came to China to visit Taishan. According to Su Ruilong's study (2003), in the 17th century, the Russian minister N. Spataru Milescu published his book Descrierea Chinei in which he depicted some details about Taishan. Besides, O. Williamson in his article the North China Trip (1869), Isabelle Williamson, in her article Old Highways in China, Baker "T'ai shan: An Account of the Sacred Eastern Peak of China”, Paul D. Bergen, “A Visit to T’ai Sham” all described Taishan in one way or another. The first and complete book Taishan and Its Religions was written by a German scholar P. Tschepe. Later on, the French scholar Edouard Chavannes compiled Tarzan: The Chinese Beliefs, which was regarded as the classic book in studying Chinese culture. Apart from the influence to the west, Taishan culture had also impact on the Asian countries such as South Korea and Japan. Zhou (2015b) ${ }^{2}$ discussed systematically about the Taishan and its cultural exchange with South Korea. Nowadays, the population of Taishan culture is becoming more and more frequent since Taishan has been awarded World's Double Heritages in Nature and Culture (1987) and the World's Geo-park (2006).

\section{The Questions of Aphasia and the Corresponding Solutions in Taishan Cultural Communication to the World}

There exist the phenomena of Aphaia in Taishan culture worldwide communication. And this can be analyzed by using Harold D. Lasswell ${ }^{3 \text { 's }}$ five-question model of communication or "Five-Ws", namingly, "Who (says) What (to) Whom (in) What Channel (with) What Effect”4.

\subsection{Say What Question}

Firstly, the "say what" question concerns the content analysis which is the basic element in cultural communication (Zhou, 2015b) . When Taishan culture is expanding to the world, because of its grandness and richness, it arouses different understandings on even the same topic. For example, the Dai Temple culture is famous for its ancient woods, engraved stones, traditional architecture, and historical antics. Each individual culture has a rich

\footnotetext{
${ }^{2}$ Zhou Ying. Culture Exchange between Taishan and South Korea [J]. Mountains \& Humanities, 2015.

${ }^{3}$ Harold Lasswell http://en.wikipedia.org/wiki/Harold_Lasswell.

${ }^{4}$ Harold D. Lasswell. The structure and function of communication in society [J]. p. 216 The scientific study of the process of communication tends to concentrate upon one or another of these questions. Scholars who study the "who", the communicator, look into the factors that initiate and guide the act of communication. We call this subdivision of the field of research control analysis. Specialists who focus upon the "says what" engage in content analysis. Those who look primarily at the radio, press, film, and other channels of communication are doing media analysis (p. 84). When the principal concern is with the persons reached by the media, we speak of audience analysis. If the question is the impact upon audiences, the problem is effect analysis.

${ }^{5}$ Ibid 2.
} 
content and long history which would be understood and interpreted differently for people's different variants such as literary backgrounds, knowledge, or age etc. Then the aphasia occurs. This is the fundamental stage in cultural communication, cannot be avoided in the transmission procedure. Take the pine named Wudafu for example (Sheng \& Zhu, 1997). In Taishan, a pine named Wudafu is a big pine tree which ever sheltered Emperor Qinshihuang when there was a rain storm. Emperor Qinshihuang was very grateful for the tree and conferred titles of noble official rank Wudafu on the pine tree. However Chinese Wu means five, and later generations did not know the meaning of the noble title and they supposed that there originally were five pine trees in the area and even planted another four pines nearby. In the Tang period, people could not make sure the meaning of the pine tree. A book named Dribs and Drabs of Literature recorded an anecdote of John Dewey who traveled in Taishan and had a rest on the rocks under the pine Wudafu. When he saw the name of the pine tree, he asked his accompany what the name meant. This accompany was not good at English and did not know the pine's history, so he answered that it was "Five-husband tree". Dewey nodded his head and answered with a sigh. This misinterpretation of the pine tree was from the basic understanding of the culture content which caused the aphasia for losing touch with historical records.

The reasons of the above question are because the differentiations in the verifications of historical facts to the long-existing traditional culture. To solve this question from the basic element, it is necessary to classify and adjust the Taishan culture contents according to different audiences with different backgrounds. For the purpose of academic study, Taishan culture should be technical, detailed and specialized. For the purpose of common appreciation to the most ordinary people, Taishan culture should be common and popularized. For the purpose of external communication to the foreigners, Taishan culture should not be so abstract, technical or general but explicit, precise and easy to understand in the target language. Therefore, the traditional Taishan culture communication needs not only the precise interpretation but also the creative and critical thoughts to hold, understand and transmit the exact Taishan culture. Furthermore, the deep understanding of Taishan culture and the exact interpretations of its essentials should consider the target language's culture and ideological modes so as to make a correct, fluent, tacit, and coherent transmission and propagation. This is a great challenge for the communicator the question of "who" in the following discussion.

\subsection{Who Question}

Secondly, the discussion of "who" is about the communicator, who look into the factors that initiate and guide the act of communication (Zhou, 2015b) ${ }^{6}$. This subdivision field is called research control analysis. In Taishan culture worldwide communication, communicator includes governmental departments, research institutions, cultural experts and scholars, guides, Taishan culture lovers and all kinds of common people etc. They are direct in connecting and understanding Taishan culture and form the main and various body of Taishan culture communication. As the communicators are different in social status or knowledgeable backgrounds, they differentiate in understanding Taishan culture, which is one of the important reasons in arousing Aphasia. Take Shigandang culture for example, people have different understandings even misunderstandings in studying and expressing this particular Taishan cultural belief. The ordinary people think that Shigandang is something about stones, knowing nothing about its culture or stories; the experts and scholars' research and study show that Shigandang is a typical belief in Taishan and has a rich and profound cultural history, being unable to transmit this understanding to the ordinary people. Thus there exists a gap between academic field and common field, which arouses cultural Aphasia. Another instance is Bixiayuanjun belief in the populace's understanding and in the academic study. The mass people know that Bixiayuanjun is the most holy and sacred Taishan host called Laonainai (meaning the senior Grandmother) whose birthday was on lunar moth March 15th. However, the title has undergone variations of "Taishan maid-Taishan niangniang-Taishan nainai-Taishan laonainai" ${ }^{\text {” }}$ in the academic studies, and people's belief on her has also undergone the development from the officials to the masses, and still more, her birthday has undergone the change from lunar month April 18th to March 15th (Zhou, 2015a) ${ }^{8}$. The Aphasia caused by different understandings and gaps among communicators will influence the communication quality and arouse misunderstandings or misapprehensions to the world.

To solve the above question, the communicators are to know Taishan cultural contents and connotations. To

\section{${ }^{6}$ Ibid 2.}

${ }^{7}$ Taishan maid refers to a young girl; Taishan niangniang refers to a middle-aged but high-rank female; Taishan nainai refers to a more honorable and respectable grandmother; Tiashan laonainai refers to a senior and most honorable and respectable almighty grandmother.

${ }^{8}$ Zhou Ying, Bixiayuanjun Belief and Taishan Culture [M], Shandong People’s Publishing House, 2015. 
the question of cultural terms and multiple tones in Chinese, the communicator should know the exact pronunciation and meaning. For example, Dou in the Doumu Palace in Chinese pronounced into dǒu, which refers to the Big Dipper but not dòu which means fight. Thus, Doumu means the mother of Big Dipper in Chinese traditional belief, however if Dou was pronounced into the falling tone and Doumu would be interpreted into fight with mother which was totally wrong. To the communicators in academic exchanges, their knowledge and wisdom in culture are of greater importance. In recent years, many Taishan culture experts and scholars have been abroad to give lectures which contributed a great deal to the propagation of Taishan culture to the world. To the communicators of guides, who play a very necessary role in interpreting and expressing Taishan culture, they are required not only to understand Taishan culture but also to explain clearly and exactly in the target language, which is an essential part in solving the problem of Aphasia.

\subsection{What Channel Question}

Thirdly, those who look primarily at the radio, press, film, and other channels of communication are doing media analysis (Zhou, 2015b) ${ }^{9}$. Of these channels, books are major ways in populating Taishan culture. However most of the traditional Taishan culture is written or recorded in Classical Chinese which would be difficult to understand in one way or another to the ordinary people. Accordingly, if Taishan culture is written on the basis of Classic Chinese books, Aphasia will occur eventually. Since the modern technology has expanded into daily life, the application of them into Taishan culture communication would be more convenient and more effective, however there existing a big and essential problem, i.e. language, as language is the carrier of culture. Nowadays, the medium language of Taishan culture communication is very limited, being mostly in Classical or Modern Chinese, English and some other foreign languages though very few. On Taishan many Chinese introductions engraved in stones are written vaguely, not to mention their corresponding translations in other languages. Take the two tablets in Bixia Temple for example, they are 东御碑亭 and 西御碑亭 in Classical Chinese, however the character 御 were engraved into 禦 with the former means the control of almighty royal power and the latter means defending. The unequal words' meaning arouses misunderstandings and then will be translated into unequal counterparts. Taishan culture, which were written or recorded into works by the missioners and travelers from their own aspect of view, sometimes would arouse misunderstandings or even wrong interpretations, for they cannot explain Taishan culture from the roots. Further is that there are divergences between Chinese and other languages, their cultures will be different so as to cause Aphasia.

Channels of communication that cause Aphasia are to solve by ways of multi-media, international languages, or more proper ways to be accepted by the majority of people. Hi-tech developments make culture communication more popular and easier to understand. Here is an example. An advertisement about traditional Filial Piety is by use of combing Chinese traditional craft of paper-cutting and modern technology of color and slides, effectively depicting the classic and modern techniques. And in Japan, some cartoons are used to explain Taishan culture. Consequently, the application of multiple and modern technology into communicative channels will make abstract things concrete, hold audience's attention, and attract the audience to enjoy and understand Taishan culture. As to the question of language, the change from Classic Chinese to modern Chinese, and modern Chinese to foreign languages needs a lot of things to do, or the interpretation of Taishan culture would be limited and reduced to fragments. What's more, if the target language user did not understand the culture, the translation would be more likely wrong, which is Aphasia from the beginning. Therefore, the proposal of using Chinese Pinyin to transcribe the typical Taishan culture to form particular and representative terms is very necessary. Once the terms are formed, they can be translated into foreign languages without any changes, which is easy to recognize and understand. This would be a great challenge for the translators who should not only have an excellent command in the target language, but also know the cultures very much, having an intercultural communicative mind to express the cultures effectively and reduce the chances of Aphasia.

\subsection{To Whom Question}

Fourthly, when the principal concern is with the persons reached by the media, we speak of audience analysis $\left(\right.$ Zhou, 2015b) ${ }^{10}$. The foreign audiences of Taishan culture is in the countries worldwide. For the purpose of their understanding, Taishan culture has been translated into foreign languages, though few, by missioners, travelers

\footnotetext{
${ }^{9}$ Ibid 2.

${ }^{10}$ Ibid 2.
} 
and sinologists etc. Some of the works have misunderstandings or wrong interpretation to Taishan culture, which results in Aphasia and directly influences the foreign audiences. For example, Kenneth Pomeranz's article: Up and Down on Mt. Tai: Bixia Yuanjun in the Politics of Chinese Popular Religion, ca. 1500-1949 (2009) had misunderstandings in discussing Bixia Yuanjun belief, which later was argued by Zhou Ying (2013), the expert in Taishan culture studies. Another example is about Shigandang culture. William Edgar Geil (1926) in his book The Sacred Five of China recorded the story of Shigandang. "In the ancient Chinese Southern Dynasty, an emperor took an adventure, in which he met a scholar named Gandang. During the journey, an assassinator intended to kill the emperor when Gandang swiftly drew out an iron stick to defend. At last, he died but saved the emperor. To show the great gratitude, the emperor ordered to set up a monument. Later on, many places imitated and set up monuments to show people's memory and appreciation for Shigandang's bravery and sacrifice. 400 years later, the stones or tablets engraved in Shigandang almost can be seen in every city. Year in year out, the deeds of Shigandang passed away, however the stones or tablets left up to now. Since the stones were from Taishan, the name was added before head by Taishan.” In this story, Shigandang was regarded as a scholar may be that in ancient China, scholars were called “士” in classic Chinese, however this word not only include scholars but also soldiers or brave men. According to ancient book records, Shigandang was a soldier but not a scholar, so it proved that Geil's story of Shigandang being a scholar was wrong. Thus, in the foreign books, Taishan culture had been changed for this reason or that, it is not hard to imagine that the Aphasia exists due to different audiences' misunderstandings.

For lack of resources and verifications, still more because of the communicators being just foreigners, some of the foreign works misunderstood or even mistaken Taishan culture. In fact Aphasia caused by these is unavoidable, but how to deal with this kind of question? and how to revise it? A proper solution is to seek common ground while reserving differences. For example, when explaining Taishan culture to the Europeans, because they know nothing about Taishan, we can have a comparison between the Greece Olympus and Taishan, to find out their similarities and differences so as to shape a vivid figure in the mind of the Europeans. But the question is that there is not always a counterpart between each of the cultural comparisons or contrasts. And even if it dies, the requirements to the communicators are to know not only one's own culture but also the target culture, for a better understanding of our culture. Although short in foreign materials, it in fact provides us with chances in translations and studies, to do some research to propagate and transmit Taishan culture.

\subsection{What Effect Question}

Lastly, if the question is the impact upon audiences, the problem is effect analysis (Zhou, 2015b) ${ }^{11}$. From this point of view, since China has improved in international status, Chinese culture is growing to be accepted in the world. Many people from the world began to visit China and attracted by the traditional and splendid cultures of which Taishan culture is a typical example. Taishan had closer and greater communication with the world, such as: Taishan and Germany cultural exchange, Taishan and South Korea cultural communication, Taishan culture experts taking part in international forum and seminar etc. These activities have strengthened the influence of Taishan culture and improved the effects of Taishan cultural communication. Many foreign TV programs have been produced to focus in Taishan and introduce its culture. Programs such as BBC documentaries Wild China and China on Four Wheels etc. have mentioned Taishan and its culture. Whereas, some introductions of these programs would not be so exact, the effects of communication can be biased which arouses Aphasia to some extent. Therefore, we are expecting communicative effects that agree with our culture but not to let it transmitted at random, which would be Aphasia by nature.

The question concerning communicative effects is to be solved by every potential communicator, media, application of modern science and technology, under the grand environment of populating Chinese traditional culture. The use of multi-media and diversification will help Taishan culture effectively and efficiently transmit to the world. And this will benefit the whole world.

\section{Proposals to Solve Aphasia Problem in Taishan Culture Worldwide Communication}

Aphasia will occur in different levels of culture communication and one of the main factors to treat this question is to hold an objective attitude which is helpful to Taishan culture and even Chinese traditional culture. To the 
question of misunderstandings or wrong interpretations, we communicators can act as Cultural Ambassadors having the duty and obligation to point out, correct, and illustrate. The teachers and students in foreign languages have more chances to communicate with foreigner, so their knowledge of Taishan culture in both Chinese and foreign language can help communicate more directly. Thus the training of them is very necessary. We have done tentative trials to train and practice our teachers and students in English major to know and express Chinese culture in English since 2012. By doing this, we formed a union called Cultural Ambassador, did research and investigation in Taishan culture, formed team in teaching and research, and achieving some fruitful results.

To the question of typical traditional terms and definitions we can propose to use Chinese Pinyin to mark so as to form the typical terms, then to explain in the target language so as to make the terms clear. In this way, our cultural particularities and essentials can be interpreted by the people in other countries. For example, Bixiayuanjun was written in Pinyin in some editorials, which is much better than in English version of Goddess of Taishan. The reason is that in English, the word God or Goddess has their religious background which is quite different from Chinese beliefs of Taoism. So the English version would arouse Aphasia in culture. In 1879, C. W. Mateer ${ }^{12}$, connected the worship of Gods with mountains, and analyzed the religious belief of Chinese to that of the westerners. He thought that just like Gods lived on the top of Olympus in ancient Greece, Chinese Gods lived on the top of Mountain Kunlun or Taishan, so that Chinese built temples on the top of mountains in order to communicate closely with Gods in heaven, which is like what Bible recorded that Abraham lived on the mountain top to worship God in heaven. Once we formed the definitions or terms in written and formal words, the understandings and interpretations would save efforts. For example, if the word Taishan is formed as a term, it can substitute words like Mt. Tai, Mt. Taishan, Tai Mountain, etc. and this will be easier in communication.

As to the cultural shock between Chinese and other countries, we can seek the common ground while reserving differences on the basic cultural identity, and this has been proved in the Spring Festival of 2015. Chinese lunar new year is a great reunion for the Chinese people all over the world, and many presidents of other countries would express their blessings and congratulations on this special moment. Most statesmen use the Chinese word Yang nian da ji (Good luck on the lunar year of goat.) Interestingly, President Obama avoided the embarrassment of the year of ram, the year of goat or the year of sheep by only saying the lunar New Year. More interestingly, the Indian Premier Narendra Modi used Chinese words to congratulate Chinese lunar New Year in his face book.

\section{Conclusion}

As Lasswell's Five-question Model has been criticized for its linear propagation, Taishan culture worldwide communication is not a stable direct way of transmission. It requires the analysis from the audience, the media, and the response, so on and so forth, to make a multi-dimensional, different aspects' study. And the exploration and research of the cultural communication to avoid or make less happening of Aphasia do benefit to our civilized and splendid culture's transmission to the world, to influence people in the world and make them know, learn and understand our culture, and then our country.

\section{Acknowledgements}

Great thanks to Culture Administration of Shandong Province for the sponsorship.

\section{References}

Cao, S. Q. (1995). The Development of 21st Chinese Literature Review and Reconstruction of Chinese Literature Discourse. A Multidimensional Study of Orientalism, 3.

Cao, S. Q. (1996a). Cultural Aphasia and Its Morbidity. Literature Debates, 2, 50-59.

Cao, S. Q. (1996b). The Basic Methodology and Measures to Reconstruct Chinese Literature Discourse. Theoretical Studies in Literature and Art, 2, 12-22.

Cao, S. Q. (1997). Re-Exploration on Reconstruction of Chinese Literature Discourse. Literary Review, 4, 43-53.

Cao, S. Q. (2006). Re-Exploration on Aphasia. Journal of Zhejiang University (Humanities and Social Sciences), 1, 11-18.

Chen, X. J. (2010). The Bilateralism of Chinese Culture in Cross-Cultural Communication-Discussion of Chinese Culture Aphasia. Journal of Jilin Technological Normal Institute, 4.

${ }^{12}$ C. W. Mateer. “T’ai san-Its Temples and Worship,” Chinese Recorder 10.5 (Sept.-Oct. 1879): pp. 361-69; 10. 6 (Nov.-Dec. 1879): pp. 403-415. cf. Su Ruilong. Study on the Culture of Mount Tai by Western Scholars. 2003. 
Cong, C. (2000). Chinese Culture Aphasia: The Defect of Our English Teachin. Guangming Daily, 2000-10-19.

Geil, W. E. (1926). The Sacred 5 of China. London: J. Murray. Chinese Version by Peng, P. et al. (2006). Ji'nan: Shandong Pictorial Publishing House.

Ma, D. H. (2007). Cultural Factors in Foreign Language Teaching. Doctorial Dissertation, Shanghai: Shanghai International Studies University.

Pomeranz, K. (2009). Up and Down on Mt. Tai: Bixia Yuanjun in the Politcs of Chinese Popular Religion, ca. 1500-1949. New History, 20, 197.

Sheng, X. C., \& Zhu, S. F. (1997). Dribs and Drabs of Literature. Shanghai: Shanghai People’s Publishing House.

Su, R. L. (2003). Study on the Culture of Mount Tai by Western Scholars. Qilu Culture Research, Vol. 2. Ji’nan: Qilu Press, 239.

Zhang, W. M., \& Zhu, H. M. (2002). Chinese Culture in University English Teaching. Qinghua University Education Research.

Zhang, W., Mi, J.-Q., \& Sun, B. (2009). Chinese Cultural Aphasia in University English Teaching and Its Solutions. Journal of Shenyang Agriculture University (Social Science), 11, 457-460.

Zhou, Y. (2009). Taishan and Its Cultural Exchange with Foreign Countries. Journal of Daizong.

Zhou, Y. (2013). Bixia Yuanjun in the Period of Late Ming and Early Qing Dynasties—A Discussion with Mr. Pomeranz. Journal of the Historical Studies, 31, 107.

Zhou, Y. (2015a). Bixiayuanjun Belief and Taishan Culture. Ji’nan: Shandong People’s Publishing House,

Zhou, Y. (2015b). Culture Exchange between Taishan and South Korea. Mountains \& Humanities. 